\title{
Effleurage Against Uterine Contractions in Active Phase First Stage Labor
}

\author{
Shentya Fitriana ${ }^{1 *}$, Novita Rina Antarsih ${ }^{2}$ \\ ${ }^{1,2}$ Midwifery department of Health Polytecnic of Ministry of Health Jakarta III \\ Jl. Arteri JORR Jatiwarna Pondok Melati Bekasi Indonesia \\ *Corresponding author's email: Shentya_f [AT] yahoo.co.id
}

\begin{abstract}
The progress of labour at active phase I is the most tiring, continuous, and most mothers begin to feel the pain. During this time many of the efforts to streamline the uterine contractions among other things with the touch of a massage. Massage on the abdomen (effleurage) is a form of stimulation of the skin which is used during the process of childbirth can induce a relaxing effect. The purpose of the study is to know the influence of massage effect against uterine contractions in parturients active phase $I$.
\end{abstract}

Quasi-experimental research draft with the design of the pretest-posttest with a control group. The sample was used for each group of 37 respondents with a purposive sampling technique. The results of the research there is a difference in the duration of uterine contraction before and after the intervention done by $p<0.05$, and the duration of the contractions of the uterus in the intervention group longer 10.270 seconds in the control group of 2,297 seconds. Effleurage massage has a significant influence on the duration of uterine contraction on at parturient active phase $I$.

Keywords-Effleurage, Contractions, Active Phase

\section{INTRODUCTION}

During labour there is an increase in the level of anxiety of pregnant women, improve pain perception, increase the duration of labour and secretions of catecholamines which reduce blood flow in the uterus. This reduces the effectiveness of uterine contractions and increases the duration of labour which can cause prolonged labour. Massage is an old technique widely used in labor and is proven effective in labor, shortening the duration of the first stage of labor, and increasing the progress of labor. [1] Effleurage is a type of massage during labour which includes light or deep pressure using a flat surface of the hands or arms on the back and abdomen of the woman in labour. This technique can reduce pain, relieve stress and anxiety, provide relaxation, comfort and reduce the duration of labor. [2)(3] This study aims to evaluate the effectiveness of effleurage during labor in the active phase of the delivery phase.

\section{METHODS}

This research is quantitative research using quasi-experiment with the design of the pretest-posttest with control group. Independent variable massage effleurage, the dependent variable of uterine contractions parturien active phase I and confounding variables are age, education, occupation, parity and ethnicity. Research conducted in Independent Practice Midwives Bekasi Area in August until October 2017. The number of samples from each group was 37 people with a purposive sampling techniques and criteria of inclusion of pregnant normal and TBJ, aterm inpartu active phase I. The analysis used a logistic regression test. 


\section{RESULTS}

Table 1. Distribution Characteristics of Respondents Parturien Active Phase I

\begin{tabular}{lcccc}
\hline \multirow{2}{*}{ Variable } & \multicolumn{2}{c}{$\begin{array}{c}\text { Intervention } \\
\text { Group }\end{array}$} & \multicolumn{2}{c}{ Control Group } \\
\cline { 2 - 5 } & $\mathbf{N}$ & $\mathbf{\%}$ & $\mathbf{N}$ & $\mathbf{\%}$ \\
\hline Age & & & & \\
$<20$ and $>35$ & 6 & 16.2 & 12 & 32.4 \\
$20-35$ & 31 & 83.3 & 25 & 67.6 \\
Education & & & & \\
Low & 7 & 18.9 & 14 & 37.8 \\
High & 30 & 81.1 & 23 & 62.2 \\
Jobs & & & & \\
Not Work & 19 & 51.4 & 19 & 51.4 \\
Work & 18 & 48.6 & 18 & 48.6 \\
Parity & & & & \\
Primigravida & 10 & 27.0 & 16 & 43.2 \\
Multigravida & 27 & 73.0 & 21 & 56.8 \\
Ethnic Groups & & & & \\
Jawa & 12 & 32.4 & 12 & 32.4 \\
Sunda & 11 & 29.7 & 11 & 29.7 \\
Betawi & 13 & 35.1 & 13 & 35.1 \\
Padang & 1 & 2.7 & 1 & 2.7 \\
\hline
\end{tabular}

Based on the chart above to see that most respondents in the age group 20-35 years of age intervention as many as 31 people (83.8\%). Education respondents most frequently found in the intervention group of higher education as much as 30 persons $(81.1 \%)$. Most respondents work don't work as many as 19 people $(51.4 \%)$ at both the intervention and control groups. Most respondents to the parity in the intervention group multigravida as much as 27 people (73\%). The most numerous ethnic Betawi $(35.1 \%)$ of 13 people both the control group and the intervention

Table 2. Distribution of The Image of The Uterine Contraction Duration On The Respondents Parturien Active Phase I

\begin{tabular}{lccccc}
\hline \multicolumn{1}{c}{ Variable } & N & Mean & SD & Min & Max \\
\hline Control Group & & & & & \\
Before & 37 & 36.49 & 4.544 & 30 & 50 \\
After & 37 & 38.78 & 6.281 & 30 & 50 \\
Intervention Group & & & & & \\
Before & 37 & 36.22 & 4.473 & 30 & 50 \\
After & 37 & 46.49 & 4.840 & 35 & 55 \\
\hline
\end{tabular}

In the table above the duration of uterine contractions in the parturient active phase, I control group 36.49 seconds before and after 38.78 seconds. On uterine contraction duration intervention group before intervention 36.22 seconds and after the intervention of 46.49 seconds.

Table 3. The Distribution of The Average Duration of The Contractions of The Uterus Before and After the Massage Effleurage on Parturien Active Phase I

\begin{tabular}{lcccccc}
\hline \multicolumn{1}{c}{ Variable } & N & Mean & SD & SE & $\begin{array}{c}\text { P } \\
\text { Value }\end{array}$ & $\begin{array}{c}\text { Mean } \\
\text { Diff }\end{array}$ \\
\hline Control & & & & & & \\
Before & 37 & 36.49 & 4.54 & 0.747 & 0.000 & 2.297 \\
After & 37 & 38.78 & 6.28 & 1.033 & & \\
Intervension & & & & & & \\
Before & 37 & 36.22 & 4.47 & 0.735 & 0.000 & 10.270 \\
After & 37 & 46.49 & 4.84 & 0.796 & & \\
\hline
\end{tabular}

From the table above, the duration of uterine contraction on parturient active phase I in the control group and the intervention has increased. The results of statistical tests obtained a p-value of 0,000 , this indicates that there is a connection duration of uterine contraction before and after both the control and intervention group. Based on the analysis of the obtained difference in the average duration of contraction between the intervention group and the control group mean difference with the control group 2,297 and group interventions 10,270. 
Tabel 4. Influence of The Distribution Characteristics of Uterine Contraction Against Respondents On Parturien Active Phase I

\begin{tabular}{lcccccc}
\hline \multirow{2}{*}{ Variable } & \multicolumn{3}{c}{ Intervension Group } & \multicolumn{3}{c}{ Control Group } \\
\cline { 2 - 7 } & Mean & T Test & $\begin{array}{c}\text { P } \\
\text { Value }\end{array}$ & Mean & T Test & $\begin{array}{c}\text { P } \\
\text { Value }\end{array}$ \\
\hline $\begin{array}{l}\text { Age } \\
\quad 20 \text { and }>35\end{array}$ & 45.00 & -0.818 & 0.419 & 35.42 & -2.405 & $\mathbf{0 . 0 2 2}$ \\
$\begin{array}{l}20-35 \\
\text { Education }\end{array}$ & 46.77 & & & 40.40 & & \\
$\begin{array}{l}\text { Low } \\
\text { High }\end{array}$ & 47.86 & 0.829 & 0.413 & 39.29 & 0.375 & 0.710 \\
Jobs & 46.17 & & & 38.48 & & \\
$\begin{array}{l}\text { Not Work } \\
\text { Work }\end{array}$ & 46.32 & -0.217 & 0.829 & 37.37 & -1.428 & 0.162 \\
$\begin{array}{l}\text { Parity } \\
\text { Primigravida }\end{array}$ & 46.67 & & & 40.28 & & \\
Multigravida & 3.375 & 0.010 & 0.992 & 36.88 & -1.652 & 0.108 \\
Ethnic Groups & 5.338 & & & 40.24 & & \\
Jawa & 45.42 & -0.453 & 0.655 & 36.67 & 0.133 & 0.895 \\
Sunda & 46.36 & & & 36.36 & & \\
\hline
\end{tabular}

Based on the table above in the intervention group T-test value of age is $-0,818$ with $\mathrm{p}$-value 0,419 ( $\mathrm{p}>0.05$ ), meaning that there is no difference in the duration of uterine contractions at age $<20$ and $>35$ by 20-35. Similarly, the value of $\mathrm{p}$ for the education, employment, parity and ethnicity, so it was concluded there was no influence of uterine contraction duration based on the characteristics of the respondents.

The value in the control group T-test $-2,405$ with $\mathrm{p}$-value $0.022(\mathrm{p}<0.05)$, this means that there is the influence of age on a control group of age $<20$ and $>35$ by $20-35$. On the group of education, occupation, ethnic origin and parity $p$ value 0.05 concluded there is no influence of uterine contractions in the control group on variables.

Table 5. The Influence of Massase Effleurage Against Uterine Contraction Duration Parturien Active Phase I In The Intervention Group and The Control Group

\begin{tabular}{llll}
\hline \multicolumn{1}{c}{$\begin{array}{c}\text { Variable } \\
\text { Independen }\end{array}$} & \multicolumn{1}{c}{ Variable Dependen } & Value F & Value P \\
\hline Corrected Model & Uterine contraction after & 9.543 & 0.000 \\
Intercept & Uterine contraction after & 720.967 & 0.000 \\
Age & Uterine contraction after & 4.636 & 0.035 \\
Education & Uterine contraction after & 5.231 & 0.025 \\
Job & Uterine contraction after & 0.170 & 0.682 \\
Parity & Uterine contraction after & 0.274 & 0.602 \\
Ethnic Group & Uterine contraction after & 4.290 & 0.042 \\
Massage Effleurage & Uterine contraction after & 37.156 & 0.000 \\
\hline
\end{tabular}

In the table above shows the influence of massage effleurage against uterine contractions parturient active phase I by controlling the variables age, education and ethnicity. From the results of processing the significance of that number looks for massage strokes is 0,000 . Because the value is well below 0.05 then $\mathrm{H}_{0}$ is rejected, so it can be inferred that there is an influence of massage effleurage on the uterine contraction parturient active phase I.

\section{DISCUSSION}

4.1 An overview of the demographic characteristics of the respondents and the uterine contractions on parturient active phase I.

The results showed the characteristics of respondents according to the chart is that most respondents in the age group 20-35 years of age intervention as many as 31 people $(83.8 \%)$. This is in line with research that states that the less risk range of maternal age to bear babies is 20-30 years and on the other side.[4-6] and extremes of age are believed to make a high-risk pregnancy more likely, which can lead to pregnancy complications[7]. This is because the age of 20-35 years is the best age to get pregnant and give birth because the reproductive organs are still healthy. 
Most respondents in the category of education higher education, the higher the level of education will impact to achieve good behaviour changes so that a high degree of women who will be more adapt to taste the pain is felt. Anxiety showed a significant relationship with a lower degree of education. [8] The higher level of anxiety was found to be more common in the urban areas, among women with a middle level of education. [9]

The work of this research most respondents on not working, mothers who are not working are expected more ready in the face of labour because it has more time to follow the activities of a group of pregnant women at the time of pregnancy, and will get a lot of experience when such activities. The higher level of anxiety was found to be more common in the urban areas, housewives, and low socioeconomic status. [9]

Parity in most of this study on a multigravida, because multigravidas having more experience in facing childbirth. This is supported by research that states that the majority of multigravida mothers are experienced high and severe anxiety and fear scores towards childbirth compared to primigravida mothers.[10]

The ethnic groups of respondents in this study varied, mostly Javanese. Ethnicity may be an important determinant of social anxiety for some ethnic groups. This is supported by research that cites astrong, positive ethnic identity can be a factor in protecting African Americans from the symptoms of anxiety and depression. [11]

4.2 The difference of uterine contraction on parturient active phase I before and after the massage effleurage

The results of the analysis of duration of uterine contraction on the parturient stage I active phase in the control group and the intervention group experienced an increase. Based on the analysis of the obtained difference in the average duration of contraction between the intervention group and the control group mean difference with the control group 2,297 and group interventions 10,270 .

Continuous labour pain affects the respiratory system, blood circulation, endocrine glands, and other bodily activities.[2,3] This is probably due to Effleurage massage makes the mother feel comfortable so that it affects the mother's hormones. This is supported by the theory which states that massage can inhibit the transmission of pain to the brain, motivate the release of endorphins, increase serotonin and inhibit the transmission of harmful nerve signals to the brain.[12] While the effect of effleurage is reducing pain, relieving stress and anxiety, relaxation, comfort and reducing the duration of labour.[2,3]

4.3 Influence of massage effleurage against uterine contraction duration on parturient phase I in the intervention group and the control group

The results of the multivariate analysis of influence of massage effleurage against uterine contractions parturient active phase I by controlling the variables age, education and ethnicity. From the results of processing the significance of that number looks for massage effleurage is 0,000 . Because the value is well below 0.05 then $\mathrm{H}_{0}$ is rejected, so it can be inferred that there is an influence of massage effleurage on the uterine contraction parturient active phase I.

Pregnant women generally worry about pain during labour and birth. As many as $80 \%$ of women in labour experience anxiety. Anxiety and stress during labour may reduce the amplitude and frequency of uterine contractions and thus, increase the duration of labour and possibly assist labour and even Caesarean section.. [13]

A non-pharmacological pain reliever approach that has the advantage of lacking side effects for the mother and fetus and also pleasing to both of them is by massage.[14] Massage will cause endorphin release and reduce ischemia by increasing local blood supply. Endorphins resemble opiates in their ability to produce analgesia and comfort. The use of massage contributes to pain relief and concern for women. Massage can be done while observing the time of contraction and gathering information from women or assessing women's coping abilities.[15] Effleurage is the most basic massage movement and is often used as an effective abdominal effleurage connecting movement to reduce the intensity of labour pain during the active phase. [14]

This research is supported by previous studies that effleurage during labour is more effective than pharmacological steps to minimize pain during labour, and is short in the first and second stages of labour.[3] and the length of labour averaged shorter by 3 hours with less need for medication.[16]

\section{CONCLUSION}

Duration of uterine contraction on average respondents experienced an increase in both the control group and group interventions. There is a significant effect on the duration of uterine contractions in the intervention group than in the control group.

Recommendations for further research do not only assess the duration of uterine contractions, but it is also expected that the study can then examine the frequency of contraction. Expected midwives able and perform actions of uterine massage strokes on the parturient mother when I active phase because of the very useful role of the family as well as boost and support. 


\section{REFERENCES}

[1]. Bolbol-Haghighi N, Masaomi S, Kazemi F. Effect of Massage Therapy on Duration of Labour: A Randomized Controlled Trial. J Clin Diagn Res. 2016;10(4):12-5.

[2]. Behmanesh F, Pasha H, Zeinalzadeh M. The Effect of Heat Therapy on Labor Pain Severity and Delivery Outcome in Parturient Women. Iran Red Crescent Med J IRCMJ. 2009;11(2):188-92.

[3]. Zaghloul M, Mossad A. Effect of effleurage on Pain Severity and Duration of labor among laboring Women. IOSR J Nurs Health Sci IOSR-JNHS. 2018;7(6 Ver. II.):1-9.

[4]. Bellieni C. Pregnancy and Undue Pressures. J Fam Reprod Health. 2016;10(3):104-7.

[5]. Gossett D, Nayak S, Bhatt S, Bailey S. What do healthy women know about the consequences of delayed childbearing? J Health Commun. 2013;18(1):118-28.

[6]. American College of Obstetricians and Gynecologists Committee on Gynecologic Practice and Practice Committee. Female age-related fertility decline. Committee Opinion No. 589. Fertil Steril. 2014;(101):633-4.

[7]. Cavazos-Rehg P, Krauss M, Spitznagel E, Bommarito K, Madden T, Olsen M, et al. Maternal age and risk of labor and delivery complications. Matern Child Health J. 2015;19(6):1202-1211.

[8]. Yu-ting Kang, Yan Yao, Jing Dou, Xin Guo, Shu-yue Li, Cai-ning Zhao, et al. Prevalence and Risk Factors of Maternal Anxiety in Late Pregnancy in China. Int J Env Res Public Health. 2016;13(468):1-11.

[9]. Hassan H, Said S, Hassanine S. Disparities of Prevalence and Causes of Maternal Antenatal Anxiety among Primigravida Pregnant Women in Egypt. Am Res J Nurs. 2017;3(1):1-15.

[10]. Tosson MM, Atwa AME, Mahmoud TM. Anxiety and Fear Level toward Childbirth among Primigravida versus Multigravida. IOSR J Nurs Health Sci IOSR-JNHS. 2019;8(2):36-44.

[11]. Stayne, Dennis M. Puberty, obesity and ethnicity. Trends Endocrinol Metab. 2004;(15):1-4.

[12]. Sadat H, Forugh F, Maryam H, Nosratollah M, Hosein S. The Impact Of Manual Massage On Intensity And Duration Of Pain At First Phase Of Labor In Primigravid Women. Int J Med Res. 2016;1(4):16-8.

[13]. Lamadah S, Nomani I. The Effect of Aromatherapy Massage Using Lavender Oil on the Level of Pain and Anxiety During Labour Among Primigravida Women. Am J Nurs Sci. 2016;5(2):37-44.

[14]. Neetu, Sheoran P, Panchal R. A Study to Assess the Effectiveness of Abdominal Effleurage on Labor Pain Intensity and Labour Outcomes Among Nullipara Mothers During 1st Stage of Labor In Selected Hospitals of District Ambala, Haryana. Int J Sci Res IJSR. 2015;4(1):1585-90.

[15]. Judie A, Nercin Brintha N. Touch and Massage On Pain Perception among Primiparturient Mothers. Res Rev J Nurs Health Sci. 2015;1(3):48-51.

[16]. Field T. Pregnancy and labor massage. Expert Rev Obstet Gynecol. 2010;5(2):177-181. 